\title{
Ageism in America: transforming therapy
}

\begin{abstract}
Drugs and Violence in Black America What Can Be Done Nationally, 55 percent of black men live below the poverty level. In Chicago, 21 percent don't work, and 20 percent have less than a high school diploma. It's not an ideal picture; the street culture of drugs and black on black violence is one manifestation of that harsh reality.
\end{abstract}

Keywords: african americans, ageism, community dynamics, interventions
Volume I Issue $3-2017$

\author{
Arthur Horton \\ Professor, Lewis University, USA
}

Correspondence: Arthur Horton, Professor, Lewis University, USA, Email ahorton756@aol.com

Received: March 22, 2016 | Published: May 02, 2017

\section{Introduction}

What can elderly black American males do during this period of political, economic and social unrest in the black world and its way of life and the nation itself. After all are they but most of the elderly challenged by societal bias and barriers which affect the elderly regardless of race. The elderly have a meaningless role and are the victims of ageism. The elderly seem to encounter a number of problems in our society: low income and status, an emphasis on youth, health problems, inadequate housing, transportation problems, elder abuse, malnutrition, crime victimization, emotional problems (particularly depression), and concerns with circumstances surrounding dying. ${ }^{1}$ But what about those individuals with sounds minds and healthy bodies?

There are many who respond to life's challenges in effective ways. They can be advocates when it comes to advancing social capital. Cities in the U.S with strong families, civic support groups, and a community- service orientation do well on social and economic mobility.

The important role as an advocate for older black males includes the following

i. Identify environmental factors impinging on the quality of the community.

ii. Provide and interpret data to show the urgency for change.

iii. In collaboration with other stakeholders, develop a vision to guide change.

iv. Analyze the sources of political power and social influence within the system.

v. Develop a step by step plan for implementing the change process.

vi. With allies lobby legislators and other policy makers.

vii. Recognize and deal with resistance.

viii. Assess the effects of advocacy efforts on the system.

All of this is done in the contest of the Appreciative Inquiry cycle --based on work by David Cooperrider, Case Western Reserve University, as indicated below.

\section{Appreciative inquiry "4-d" cycle discovery}

i. Our changing world. ii. Organizational or community Positive Core.

iii. Opportunity context.

\section{Destiny}

i. Initiatives.

ii. Pilots (operational goals and specific objectives in the form of a stated mission).

iii. Improvisation.

\section{Dreams}

i. Working Together to Create a Breakthrough Organizational or Community Design.

ii. Articulation of Vision \& Future We Want.

\section{Design}
i. Principles.
ii. Provocative Propositions.
iii. Ideals.

\section{The therapeutic alliance}

The goal of therapy is to change behaviour; the change process entails: being in a current state, a transitional state, and lastly the desired state. This process puts great demands on people both the change agent and client or clients in group setting. In the case of African American clients as argued by Amos N. Wilson, there are two challenges: fantasy experiences and/or stereotypy behaviours. ${ }^{2}$ In seeking to win full acceptance and equality in with the larger white society, blacks have tried nearly possible means available to them to attain such.... Yet, none of these methods singularly or in combination have been very successful. The final outcome has been for many blacks to lapse into stereotypy. The flexibility required for efficient problem solving, the ability to follow new directions, is adversely affected or completely negated by ensuing reactions to frustrations. Thus, they may engage in fantasies of having reached their goals, or vicariously identifying with whites by acting "whites" or pretend that America has no racial problems, only a problem of economics, they may enter into their own fantasy world of sexualized dancing, partying -- much of the hip hop community-- with constant sexual play (including strip Joints or porn mediums such as the internet, smart phone apps)or compulsive alcohol or drug use with without compulsive gambling. In many instances there is the use of some type of weapon to resolve 
personal issues and conflict. In the actual practice of therapy, but one not based on magical thinking, resistive and repetitive but not getting anywhere, there is an unfreezing of not desired

\section{Behaviour and refreezing of desired behaviour(s)}

More recently, two renowned researchers at UCLA have furthered the understanding of the brain, mind and sense of self. Dr. Marian Diamond is a professor of biology at that university and Dr. Arnold Scheibel is director of UCLA's Brain Research Institute. They have provided insight into the plasticity of the brain itself. The environment is fluid, human experience is fluid, and the brain adapts and is shaped by that fluidity.

In experiments with rats they were able to show that at any age there was change in the structure of the out layers of the brain when the rats lived in enriched environments, in contrast to when they lived in impoverished environments. In the impoverished environment, the brain decreases its dimensions, and in the enriched environment, it naturally increases its dimensions. Whether we are dealing with rats, cats, dogs, monkeys, or man all of them can change their brains in response to a positive environment. Thus, it looks very much as if both from animal data and now from human data, that the more complex and resonant a brain we build up for ourselves, by the enrichment of interaction with the world around us, that brain, in a sense, is apparently better fortified against the possible later ravages of something like dementia or Alzheimer's disease. The products of the brain affects the structure of the brain and better sustains the sense of self at later ages. The nerve cells are designed to be stimulated - i.e. challenges, fun things to do, and new directions to one's life."The brain stem has an area called the reticular formation," says Dr.Scheibel, "[it's] wired to respond selectively to the new and exotic. This was a survival mechanism when we were on the lockout for predators. Now, new challenges [activate] your reticular formation and stimulate growth of dendrites." For even though adult humans don't grow new neurons -- unlike infants -lifelong mental stimulation can nourish growth of new connections called dendrites and synapses (Wall Street Journal, Nov. 21, 1994).

Focusing is a term borrowed from the world of photography, in which it represented a significant technical breakthrough. Early cameras only had pin holes. The photographer's emphasis was determined by where he was standing. If she was in front of the tree, the tree dominated the picture, even if William Howard Taft was standing next to it. The advent of lenses changed all that. The photographer could focus on a person, one flower in a bouquet, or even one petal. The relationship of the figure to the background could be controlled simply by making adjustments. Now the photographer could frame the world she wanted to portray. Focusing is the ability of the mind to mediate the myriad of sensory and perceptual data that presents itself as an essential aspect of

Table I Creative, intuitive side(Right).You can value the difference to catalyze creativity. Below is a listing of some of the differences

\begin{tabular}{llll}
\hline I & Rules & I & Freedom \\
2 & Standardization & 2 & Variation \\
3 & Conformity & 3 & Creativity \\
4 & Memory for specific facts & 4 & Memory for essence \\
5 & Regularity & 5 & Novelty \\
\hline
\end{tabular}

consciousness. Besides voluminous information that provides the basis of action, the human mind must also address the complexity which it encounters and perceives as reality. To focus is to decompose, simplify, and specify information. To decompose information once perceived by the mind is to break it down into its component parts. This is key to resolving any puzzling decision; with complex phenomena it is necessary to decompose it into its most important components and the recombine the results to make the decision -form a judgment. For example, most people do this when they do more difficult mathematical problems.

Ever since George A. Milken of Harvard University discovered "the magical number of seven - plus or minus two" -- that is the inability of the human mind to hold more than five to nine bits of information in short-term memory -- there has developed an increasing recognition of the human mind's limitation for processing information. There are, writes Herbert A. Simon of Carnegie-Mellon University, "limits to human rationality." To emphasize these limits, Simon developed his principle of bounded rationality. The capacity of the human mind for formulating and solving complex problems is very small much of the time compared with the size of the problem whose solution is required for objectively rational behavior in the real world -- or even for a reasonable approximation to such objective reality. It is, in part, for his work on uncovering and describing the limits to human cognitive abilities that Simon was awarded the Nobel Prize in Economics (Simon, 1957)

\section{Synergy and gestalts -- the creative process \\ Levels of communications}
i. High Synergistic (Win/Win)
ii. TRUST Respectful (Compromise)
iii. Low Defensive (Win/Lose or Lose/Win)
iv. Low High

\section{Cooperation}

Insecure people think that all reality should be amenable to their paradigms. They have a high need to convert others, in other word "my way or forget it". However, the important achievement is to accept the difference in what is prized by the other person (dreams, wants and needs).

\section{Transforming the duality of the brain}

The left brain uses the language of facts, figures, specifics and parts. The right brain entails sensing, at the level of the gestalt, the whole, the relationship between the parts. Your own internal synergy is within your realm of being. You can respect both sides of your own nature -- the analytical Side (Left in the table) and the creative, intuitive side (Right) (Table 1). You can value the difference to catalyze creativity. Below is a listing of some of the differences. 


\begin{tabular}{|c|c|c|c|}
\hline 6 & Rigid order & 6 & Flexibility \\
\hline 7 & "Normality" & 7 & Uniqueness \\
\hline 8 & Differences equal deficits & 8 & Sameness equals oppression \\
\hline 9 & Preconceive & 9 & Improvise \\
\hline 10 & Precision & 10 & Approximate \\
\hline II & Logical & 11 & Psychological \\
\hline 12 & Egocentric & 12 & Global, sociocentric \\
\hline 13 & Convergent & 13 & Divergent \\
\hline 14 & Controlled & 14 & Expressive \\
\hline 15 & Meanings are universal & 15 & Meanings are contextual \\
\hline 16 & Direct & 16 & Indirect \\
\hline 17 & Cognitive & 17 & Affective \\
\hline 18 & Linear & 18 & Patterned \\
\hline 19 & Mechanical & 19 & Humanistic \\
\hline 20 & Unison & 20 & Individual in group \\
\hline 21 & Hierarchical & 21 & Democratic \\
\hline 22 & Isolation & 22 & Integration \\
\hline 23 & Deductive & 23 & Inductive \\
\hline 24 & Scheduled & 24 & Targeting opportunity \\
\hline 25 & Thing focused & 25 & People focused \\
\hline 26 & Constant & 26 & Evolving \\
\hline 27 & Sign oriented & 27 & Meaning oriented \\
\hline 28 & Duty & 28 & Sentiment \\
\hline
\end{tabular}

At this juncture we examine a most important aspect of the process of change for an addicted person. The emotional cycle of change.

\section{Emotional cycle of change}

$\mathrm{O}$

$\mathrm{P}$

Phase I (Uniformed optimism)

Phase IV

$\mathrm{T}$

(Informed Optimism)

I

M

I

S

M

$\mathrm{P}$

E

$\mathrm{S}$

Phase III

Phase II (Uniformed Pessimism)

$\mathrm{S}$

Reality hits 
(A) Determination and commitment

Or

I__ Reality Check ( at best SWAT analysis)

i.e., my, immediate situation

(B) Giving Up (Worst Case, Hopelessness and Despair)

M

I

S

M

At any rate the self of the individual personality presides over the entirety of all the processes of change as presented above. I digress to important information, the germaneness of which as we conclude in a summation of properties of the self.

The self integrates these brain hemispheric functions. The "why" questions at start to the end of the change process are pivotal.

i. Sets the tone of the therapeutic experience and need for feedback which is mutual.

ii. Behaviour drives results which correlate directly with all participants' level of motivation.

iii. Predicated on consistency and accountability.

iv. Role modelling by the practitioners.

v. Raises level of awareness for all participants.

vi. In a group setting, situational leader is accepted.

\section{Acknowledgements}

None.

\section{Conflict of interest}

Author declares there is no conflict of interest in publishing the article.

\section{References}

1. Zastrow CH. Understanding Human Behaviour in the Social Environment. Belmont, CA, 9th edn. Brooks/Cole empowerment series, Australia; 2013.

2. Wilson AN. The Developmental Psychology of the Black Child. Africana Research Publications, New York, USA; 1987.

3. http://www.hbo.com/addiction/understanding_addiction/12_pleasure pathway.html

4. http://www.apa.org/topics/addiction/index.aspx

5. http://www.hopenetworks.org/addiction/Children $\% 20$ of $\% 20$ Addicts. html

6. http://www.health.am/psy/more/addiction-and-the-family/

7. http://helpguide.org/mental/drug_substance_abuse 